\title{
A SiC-Based Converter as a Utility Interface for a Battery System
}

\author{
Hui Zhang ${ }^{1}$, Leon M. Tolbert ${ }^{1,2}$, Burak Ozpineci ${ }^{2}$, Madhu S. Chinthavali ${ }^{2}$ \\ hzhang18@utk.edu, tolbert@utk.edu,ozpinecib@ornl.gov, chinthavalim@ornl.gov \\ ${ }^{1}$ Electrical and Computer Engineering \\ The University of Tennessee \\ Knoxville, TN 37996-2100 \\ ${ }^{2}$ Power Electronics \& Electric Machinery Research Center \\ Oak Ridge National Laboratory \\ Knoxville, TN 37932
}

\begin{abstract}
The purpose of this work is to provide validated models to estimate the performance of a SiC-based converter as a utility interface in battery systems. System design and modeling are described in detail. Simulations are done for both a SiC JFET converter and its $\mathrm{Si}$ counterpart based on the quality of tested devices. The simulation results indicate that in both charging and discharging modes, the $\mathrm{SiC}$ converter has a better performance compared to the Si one. (1) With the same heatsink size and ambient temperature, great advantages in efficiency and junction temperatures were found in the SiC-based converter. (2) With the same thermal limit, large savings in system weight and volume combined with a high efficiency were found in the $\mathrm{SiC}$ based converter.
\end{abstract}

Keywords - Silicon carbide (SiC), JFET, Schottky diode, inverter, modeling, battery.

\section{INTRODUCTION}

Silicon carbide $(\mathrm{SiC})$, as an alternative choice of material for power electronics, has been widely known. It has advantages in electrical breakdown field, thermal conductivity, electron saturated drift velocity, and irradiation tolerance. These make the $\mathrm{SiC}$ devices able to work at higher voltage, temperature, and frequency, and produce less power losses at the same time. As a result, a system composed of $\mathrm{SiC}$ devices is more efficient and reliable. Therefore, $\mathrm{SiC}$ power electronics devices are expected to substitute for $\mathrm{Si}$ counterparts in highpower, high-temperature, and high-frequency applications [1-4]. At present, most $\mathrm{SiC}$ applications focus on military, aerospace, and geothermal, where cost is not a critical factor. Utility and automobiles are two other potential applications, which are drawing more attention. As the cost of $\mathrm{SiC}$ devices decreases, there will be more application areas for $\mathrm{SiC}$ devices.

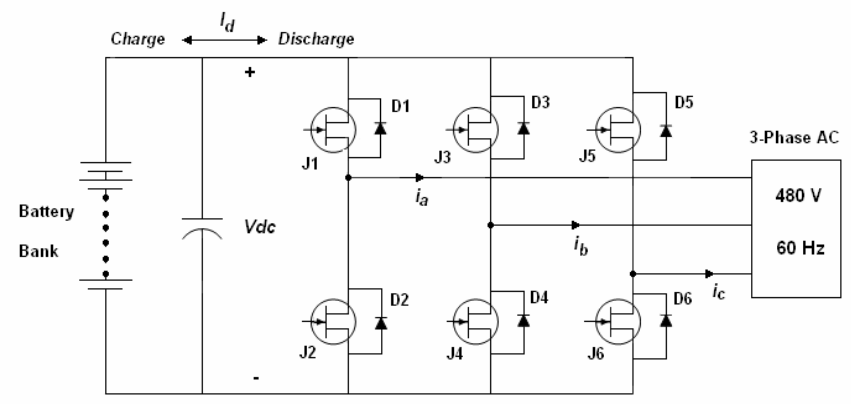

Fig. 1. Inverter interface system structure.
A qualitative description of $\mathrm{SiC}$ devices is not enough to guide device designers and customers. Device, circuit, and system models and specific quantitative results for different applications are required. In this work, simulations of a $\mathrm{SiC}$ based converter working as an interface between a battery bank and a utility were performed. Quantitative advantages of this system compared to its Si counterpart were obtained based on the quality of tested devices.

\section{Utility InTERface System Design}

The utility interface system is composed of a battery bank and a converter. The battery bank is to be charged and discharged from the utility via the three-phase, full-bridge converter (refer to Fig. 1). The converter works as a rectifier during the charging of the battery, and an inverter for discharging.

\section{A. DC Link Voltage}

The converter is controlled by Sinusoidal Pulse Width Modulation strategy (SPWM). The relationship between line voltage, $V_{l l}$, and dc link voltage, $V_{d c}$, can be expressed as (1), where $M$ is modulation index [5]. If $0 \leq M \leq 1$, the minimum dc link voltage is for $M=1$. For $V_{l l}=480 \mathrm{~V}, V_{d c}(\min )=783.8 \mathrm{~V}$.

$$
V_{l l}=M \cdot \frac{\sqrt{3} V_{d c}}{2 \sqrt{2}}
$$

\section{B. Battery Bank}

The battery bank must be designed to meet the minimum requirement of the dc link voltage. A Hawker Genesis brand, $13 \mathrm{Ah}$ rated lead acid battery (with a nominal voltage of $12 \mathrm{~V}$ ) is considered here. Its property curves are shown in Fig. 2 [6]. During discharging, the output voltage of the battery slowly decreases due to the decrease of open-circuit voltage of the battery. Thus, at the end of discharge, the open-circuit voltage of the battery is the minimum, and this determines the number of batteries needed in series. As shown as Fig. 2(c), after the battery is discharged to about $40 \%$ state of charge (SOC), there will be a sharp increase in battery discharge resistance. Consequently, running the battery with a SOC lower than $40 \%$ would require a large number of batteries in series. Specifically, the number of batteries in series can be $43 \%$ more when the batteries are discharged to $20 \%$ SOC instead of $40 \%$ 


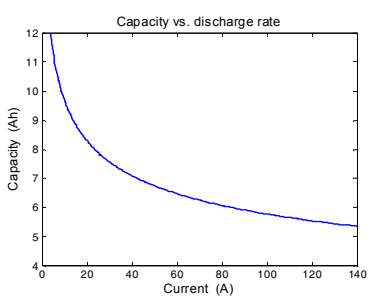

(a)

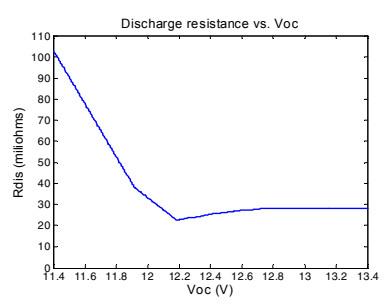

(c)

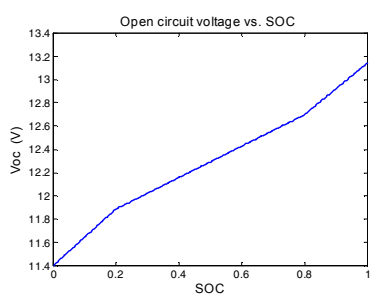

(b)

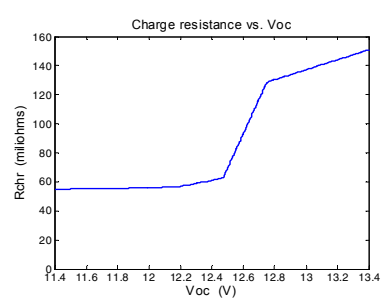

(d)
Fig. 2. Characteristics of Hawker Genesis battery (13Ah).

SOC. Therefore, the optimum number of batteries in series is 84 corresponding to the end of discharge at $40 \%$ SOC in this case. If the battery bank is discharged by a constant current of 120 A, it can last 2.33 hours from full charge to $40 \%$ SOC.

\section{Converter}

The converter has a standard 3-phase full-bridge topology with six switches and six anti-parallel diodes. To meet the requirements of this system, the ratings of these devices must be larger than the maximum of the current and the voltage that they are supposed to handle. The maximum voltage occurs when the batteries are fully charged, and this value is larger than the nominal voltage of batteries. The maximum current occurs at the beginning of the discharge of batteries. Based on the above discussion and also considering the availability of devices, the selected devices are shown in Table I.

TABLE I. DEVICES USED IN THE CONVERTERS

\begin{tabular}{|c|c|c|c|}
\hline Item & $\begin{array}{c}\text { Voltage } \\
\text { rating }\end{array}$ & $\begin{array}{c}\text { Current } \\
\text { rating }\end{array}$ & Part number \\
\hline SiC JFETs & 1200 & $14 \mathrm{~A} \times 21$ & SiCED \\
\hline SiC Schottky diodes & 1200 & $10 \mathrm{~A} \times 30$ & Cree, CSD10120 \\
\hline Si IGBT Module & 1200 & $300 \mathrm{~A}$ & Powerex, CM300DY-24NF \\
\hline
\end{tabular}

\section{MODELING}

Fig. 3 shows the modeling methodology of this system. The battery model and converter model are the two basic components.

\section{A. Converter Model}

The converter models have three parts, namely single device models, converter power loss models, and thermal models. Single device models are the basis of the converter models, which describe device characteristics in both conduction and switching periods under different temperatures. The converter power loss models use an averaging technique to

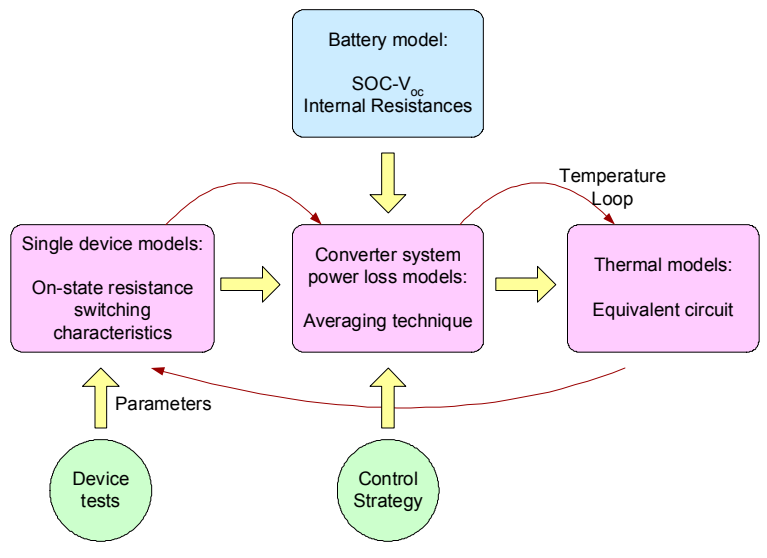

Fig. 3. Modeling methodology for battery-converter system.

estimate the system power loss under a specific control strategy. Their inputs are device characteristics given by single device models and the system operation variables (converter dc side voltage, ac side current, modulation index, and power factor) calculated by the battery model. Their outputs are the power losses of switches and diodes. These power losses are input into the thermal models to get real-time junction temperatures of devices. At the same time, the temperatures are fed back to the single device models in order to update device characteristics. A brief summary of specific mathematical models is presented in Appendix II. More details can be found in papers [7-11].

\section{B. Battery Model}

Developing a battery model is beyond this work. It is reasonable to use a basic equivalent circuit shown in Fig. 4 to describe the performance of batteries. This information is only needed to generate approximate voltage and current levels expected from a typical battery. The parameters of Hawker Genesis batteries used in this system are from [6].
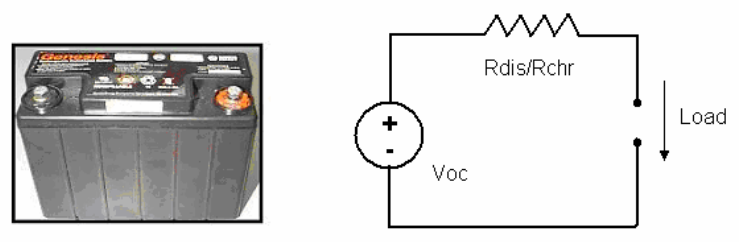

Equivalent circuit

Fig. 4. Hawker Genesis battery $(13 \mathrm{Ah}, 12 \mathrm{~V})$ and its equivalent circuit.

\section{SimUlations AND DISCUSSIONS}

In this work, the utility has a line voltage of $480 \mathrm{Vrms}$, a frequency of $60 \mathrm{~Hz}$, and the converter was controlled to produce current at unity power factor. The battery bank is composed of 84 13Ah Hawker Genesis batteries in series. The battery bank is discharged at a constant current of $120 \mathrm{~A}$ from full charge to $40 \% \mathrm{SOC}$, and the power is delivered to the utility through the converter. Vice versa, it is charged at a 
constant voltage of $1109 \mathrm{~V}$ from $40 \%$ SOC to full charge, and the power is provided by the utility through the converter. In both discharge and charge processes, the converter works as an interface. They are expected to consume as little power as possible. The power losses and efficiencies of the $\mathrm{SiC}$ and $\mathrm{Si}$ converters based on the devices in Table I were computed for different conditions using the technique presented in Part III. Some parameters obtained from device tests used in the simulations are listed in Table II.

TABLE II. DEVICE Characteristics (At RoOM TEMPERATURE)

\begin{tabular}{|l|c|c|}
\hline \multicolumn{1}{|c|}{ Characteristics } & $\mathrm{Si}$ & $\mathrm{SiC}$ \\
\hline IGBT/JFET on-state resistance & $6.6 \mathrm{~m} \Omega$ & $7.4 \mathrm{~m} \Omega(0.156 \Omega / 21)$ \\
\hline IGBT/JFET voltage drop when $\mathrm{I}=0$ & $0.83 \mathrm{~V}$ & 0.0 \\
\hline IGBT/JFET transconductance & $61.2 \mathrm{~S}$ & $14.7 \mathrm{~S}(0.7 \mathrm{~S} \times 21)$ \\
\hline Diode on-state resistance & $8.6 \mathrm{~m} \Omega$ & $2.1 \mathrm{~m} \Omega(63.8 \mathrm{~m} \Omega / 30)$ \\
\hline Diode reverse recovery charge & $13 \mu \mathrm{C}$ & $0.84 \mu \mathrm{C}(28 \mathrm{nC} \times 30)$ \\
\hline
\end{tabular}

Using MATLAB Simulink, two sets of simulations have been done for both the SiC-based and Si-based systems for a charge cycle and a discharge cycle, respectively. In the first set of simulations, the ambient temperatures and the heatsink sizes were the same for the $\mathrm{Si}$ and $\mathrm{SiC}$ systems. In the second set of simulations, the heatsinks were selected to limit the maximum junction temperature to $125^{\circ} \mathrm{C}$ for both the $\mathrm{SiC}$ and $\mathrm{Si}$ devices.

Based on the specific system information discussed previously, the battery system model worked out the unknown system parameters required for power losses calculation. As shown as Fig. 5 (a), the peak current flowing through the converters changed slowly during the discharge cycle. While it decreased quickly as the open-circuit voltage of the battery bank increased during the charge cycle, and the average of the charge current is much lower than that of the discharge current (Fig. 5 (b)). Thus, the charge cycle is much longer than the discharge cycle, and the power involved in the charge cycle is much lower than that in the discharge cycle.

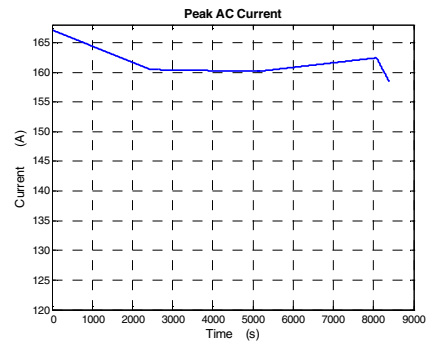

(a) discharge

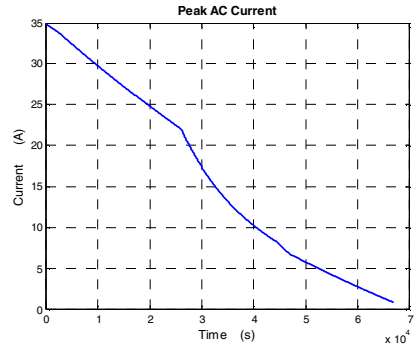

(b) charge
Fig. 5. AC side current under two modes $(100 \%-40 \%$ SOC).

\section{A. With the Same Heatsink Size and Ambient Temperature}

With variation of the system variables, power losses, device junction temperatures and parameters change dynamically. The change processes obtained from simulations are shown in Figs. 6-9 (for discharge) and Figs. 10-13 (for charge).

During discharge, the great power savings of the $\mathrm{SiC}$ Schottky diode due to lower on-state resistance (Fig. 7 (b)) and (a) $\mathrm{SiC} \mathrm{JFETs/Si} \mathrm{IGBTs}$

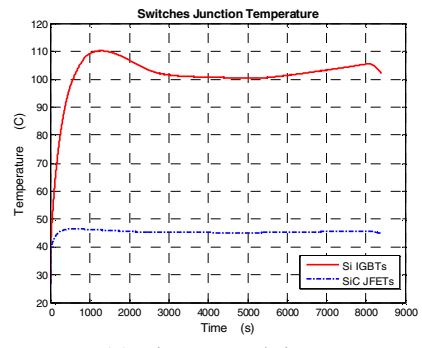

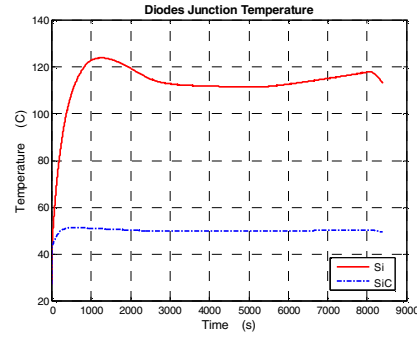

(b) Diodes
Fig. 6. Device junction temperatures during discharge.

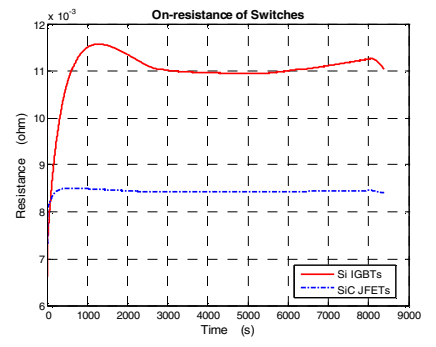

a) $\mathrm{SiC} J F E T s / \mathrm{Si}$ IGBTs

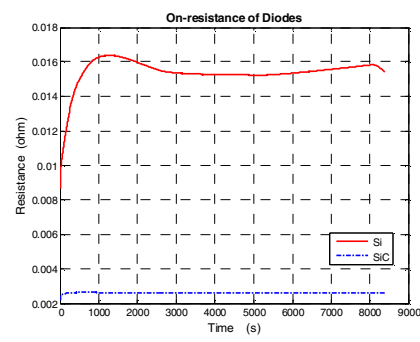

(b) Diodes
Fig. 7. Device on-state resistances during discharge.

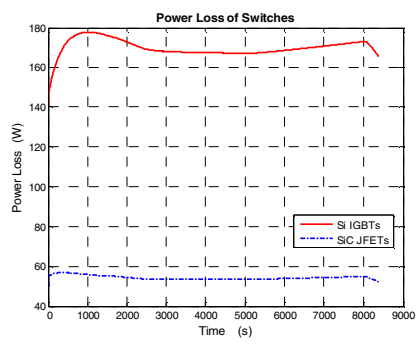

a) $\mathrm{SiC} \mathrm{JFETs/Si} \mathrm{IGBTs}$

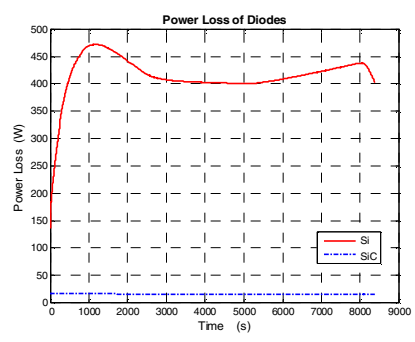

(b) Diodes
Fig. 8. Device power losses during discharge (single device).
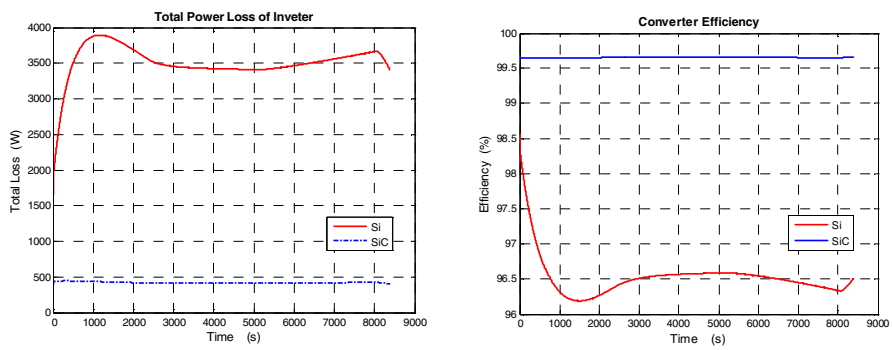

Fig. 9. System power losses and efficiency during discharge.

better reverse recovery characteristics reduced the temperature rise of the $\mathrm{SiC}$ system dramatically (Fig. 6). Temperature has a significant effect on device characteristics, especially on the mobility of electrons and holes that dominates the dependency on temperature of the on-state resistance of devices. Although the on-state resistance of the SiC JFET is larger than that of the Si IGBT at room temperature (see Table II), a lower on-state resistance was found in the SiC JFET as shown in Fig. 7 (a) because of its much lower junction temperature (see Fig. 6 (a)). 
This further reduced system power losses and improved efficiency of the SiC converter (see Fig. 8 and Fig. 9). Consequently, the junction temperature rise of the $\mathrm{SiC}$ devices is less than that of the Si devices (refer to Appendix II). As shown in Fig. 3, the junction temperatures continued to affect the device characteristics, and repeat the above dynamic process until a steady state is reached.

During charge, a similar process exists. Again, the performance of the SiC Schottky diode is much better than that of the $\mathrm{Si}$ diode in both conduction and switching states (Figs. 10-12 (b)). For the SiC JFET, its on-state resistance is larger than that of the Si IGBT in most of the period as shown in Fig. 11 (a). It seems that the conduction loss of the SiC JFET should be larger. However, this is not the only contribution to the conduction loss of a switch. The loss due to the voltage drop across Schottky barrier or $p n$-junction is also an important part, and it dominates when current is small (refer to the equations in Appendix II). As the device characteristics provided in Table II, the voltage drop across the Si IGBT at zero current is much higher than that of the SiC JFET. So the conduction loss of the Si IGBT due to this voltage drop is relatively large. Since the current during charge is small, this part of conduction loss dominates the overall conduction loss. That is to say, the overall conduction loss of the SiC JFET is smaller than that of the Si IGBT. As for switching losses, the $\mathrm{SiC}$ JFET can also compete with the Si IGBT because of no tail current during turn off. Thus, the total of power losses of the $\mathrm{SiC}$ JFET is smaller than that of the Si IGBT as shown in Fig. 12(a). Combining the better performances of the SiC JFET and the $\mathrm{SiC}$ Schottky diode, the $\mathrm{SiC}$ converter is better than the $\mathrm{Si}$ one under charge mode (see Fig. 13).

No matter discharge mode or charge mode, the $\mathrm{SiC}$ converter shows better performance than the $\mathrm{Si}$ one in efficiency and juncture temperature. More clearly, the specific improvements are summarized in Table III.

TABLE III. COMPARISON OF SIC AND SI CONVERTER

\begin{tabular}{|c|c|c|c|c|}
\hline \multicolumn{5}{|c|}{ Condition A: With the same heatsink size and ambient temperature } \\
\hline $\begin{array}{c}\text { Operation } \\
\text { Mode }\end{array}$ & $\begin{array}{c}\text { Average } \\
\text { Junction } \\
\text { temperature } \\
\text { reduction }\left({ }^{\circ} \mathrm{C}\right)\end{array}$ & $\begin{array}{c}\text { Average } \\
\text { efficiency } \\
\text { improvement } \\
(\%)\end{array}$ & $\begin{array}{c}\text { Average } \\
\text { power loss } \\
\text { reduction } \\
(\mathrm{kW})\end{array}$ & $\begin{array}{c}\text { Energy } \\
\text { savings in } \\
\text { one cycle } \\
(\mathrm{kWh})\end{array}$ \\
\hline Discharge & $56 / 63$ & 3.3 & 3.09 & 7.20 \\
\hline Charge & $7 / 11$ & 5.5 & 0.45 & 8.37 \\
\hline \multicolumn{5}{|c|}{ Condition B: With the same maximum junction temperature $\left(125^{\circ} \mathrm{C}\right)$} \\
\hline Discharge & $4 / 3$ & 3.1 & 2.93 & 6.83 \\
\hline Charge & $1 / 5$ & 5.4 & 0.45 & 8.30 \\
\hline
\end{tabular}

Note: The two numbers in column "Junction temperature reduced" are for JFET(IGBT) and diode, respectively.

\section{B. With Different Sizes of Heatsinks}

In high power applications, the size of a heatsink could account for $1 / 3$ of total system volume. How to reduce the size of heatsink is always an issue. To show the benefit of a $\mathrm{SiC}$ converter in this aspect, the simulation is designed to run the $\mathrm{SiC}$ and $\mathrm{Si}$ devices to the same temperature $\left(125^{\circ} \mathrm{C}\right)$ by using different sizes of heatsinks. The results indicate that the size of the heatsink required by the $\mathrm{SiC}$ converter is reduced to about

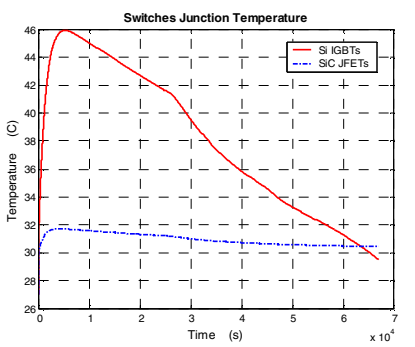

(a) $\mathrm{SiC}$ JFETs/Si IGBTs

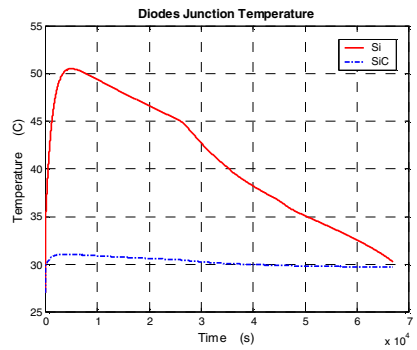

(b) Diodes
Fig. 10. Device junction temperatures during charge.

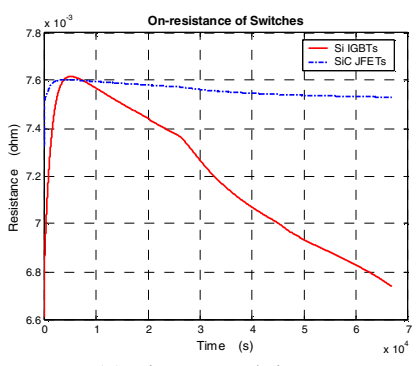

(a) $\mathrm{SiC}$ JFETs/Si IGBTs

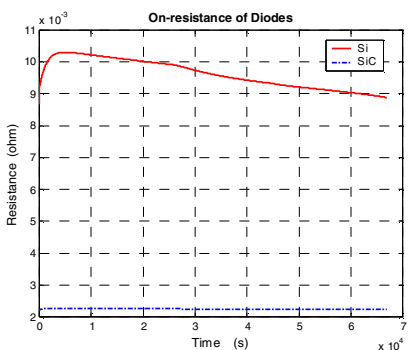

(b) Diodes
Fig. 11. Device on-state resistances during charge.

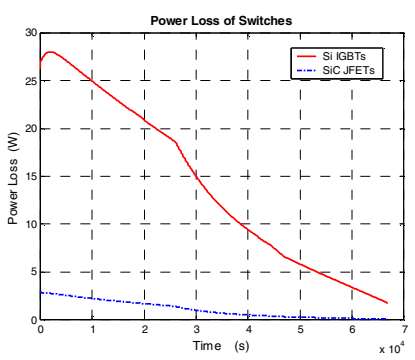

(a) $\mathrm{SiC}$ JFETs/Si IGBTs

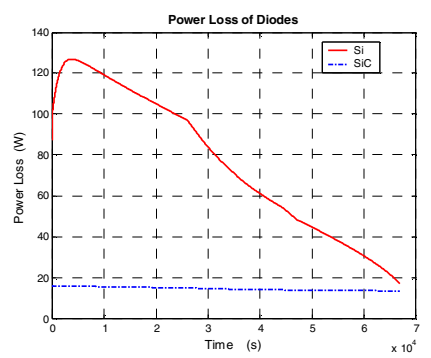

(b) Diodes
Fig. 12. Device power losses during charge (single device).
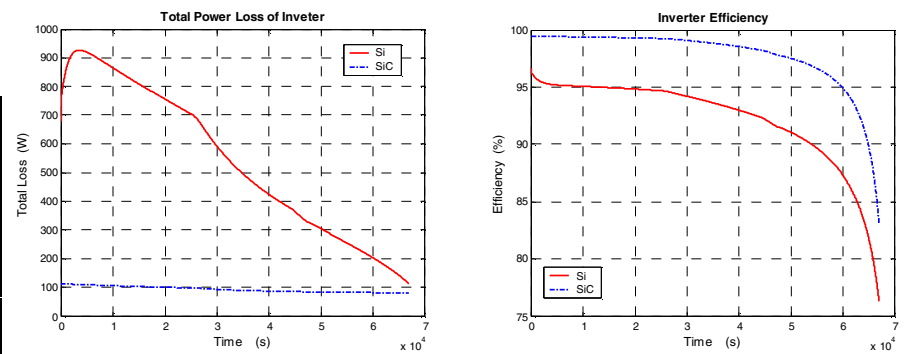

Fig. 13. System power losses and efficiency during charge.

$1 / 25$ of that of the Si converter under the same cooling method (forced cooling with fan) or $4 / 5$ when the $\mathrm{SiC}$ inverter is naturally cooled, and at the same time the efficiency is improved by $3.1 \%$ for discharge, $5.4 \%$ for charge.

In addition, when the average junction temperatures of $\mathrm{SiC}$ devices change from $45^{\circ} \mathrm{C} / 50^{\circ} \mathrm{C}$ (for the $\mathrm{SiC}$ JFET/the $\mathrm{SiC}$ Schottky diode, respectively) under Condition A (in Table III) to $97^{\circ} \mathrm{C} / 116^{\circ} \mathrm{C}$ under Condition $\mathrm{B}$, the efficiency of the $\mathrm{SiC}$ converter during discharge is lowed by only $0.2 \%$. This indicates that the influence of temperature on the $\mathrm{SiC}$ devices is 
very small. Thus, more benefits can be achieved if $\mathrm{SiC}$ devices are used in high-temperature applications.

\section{CONCLUSIONS}

In both charging and discharging modes, the $\mathrm{SiC}$ converter has a better performance over the $\mathrm{Si}$ one. With the same external thermal condition (the same heatsink size and ambient temperature), great advantages in efficiency and junction temperatures were found for the SiC-based converter. On the other hand, with the same thermal limit, large savings in system weight and volume combined with a high efficiency were found in the SiC-based converter. Therefore, this SiC-based battery converter system is expected to substitute for its $\mathrm{Si}$ counterpart in systems like automobiles where weight and volume are the critical factors, the $\mathrm{SiC}$ converter can be designed with a simple and compact cooling system. For solar systems where efficiency and reliability is more important, the $\mathrm{SiC}$ converter can have a normal cooling system in order to achieve high efficiency and reliability. Even though $\mathrm{SiC}$ devices are expensive, the large savings can make them very cost-effective.

\section{REFERENCES}

[1] L. M. Tolbert, B. Ozpineci, S. K. Islam, M. Chinthavali, "Wide bandgap semiconductors for utility applications," IASTED International Conference on Power and Energy Systems (PES 2003), February 24-26, 2003, Palm Springs, California, pp. 317-321.

[2] NEDO, "Development of ultra low loss power devices technology," www.nedo.go.jp/kankobutsu/ pamphlets/shindenryoku/development.pdf.

[3] T. Ericsen, "Future navy application of wide bandgap power semiconductor devices," Proceedings of the IEEE, vol. 90, Issue 6, June 2002, pp. 1077-1082.

[4] P. G. Neudeck, L. G. Matus, "An overview of silicon carbide device technology," Ninth Symposium on Space Nuclear Power Systems, Albuquerque, New Mexico, Jan. 12-16, 1992.

[5] N. Mohan, T. M. Undeland, W. P. Robbins, Power Electronics, $2^{\text {nd }}$ Edition, John Wiley \& Sons Inc., 1995.

\section{APPENDIX I. SYMBOLS}

\begin{tabular}{|ll|ll|}
\hline$V_{D}$ & Diode voltage when current is 0 & $E_{c}$ & Breakdown voltage \\
$V_{I}$ & IGBT voltage when current is 0 & $\varepsilon$ & Dielectric constant \\
$R_{D}$ & On resistance of diode & $V_{d c}$ & DC bus voltage \\
$R_{J}$ & On resistance of JFET & $g_{m}$ & Transconductance \\
$R_{I}$ & On resistance of IGBT & $V_{G H}$ & Highest gate voltage \\
$I$ & Peak forward current & $V_{G L}$ & Lowest gate voltage \\
$J$ & Current density & $V_{t h}$ & Threshold voltage \\
$M$ & Modulation index & $P_{j}$ & Power loss of JFET/IGBT \\
$\phi$ & Phase angle of current & $P_{d}$ & Power loss of diode \\
$f_{c}$ & Switching frequency & $R_{j c}$ & Thermal resistance \\
$t_{t a i l}$ & Duration of tail current of IGBT & & from junction to case \\
$k_{t}$ & Tail current factor for IGBT & $R_{c h}$ & Thermal resistance \\
$I_{R}$ & Peak reverse current of diode & & from case to heatsink \\
$t_{r r}$ & Reverse recovery time of diode & $R_{h a}$ & Thermal resistance \\
$S$ & Snappiness factor of diode & & from heatsink to ambient \\
$A$ & Active area of device & $C$ & Thermal capacitance \\
\hline
\end{tabular}

[6] V. Johnson, M. Keyser, "Testing, analysis, and validation of a Hawker Genesis lead acid battery model in ADVISOR," www.ctts.nrel.gov/ analysis/documents/hawker_validation.html, Mar. 1999.

[7] H. Zhang, M. Chinthavali, B. Ozpineci, L. M. Tolbert, "Power losses and thermal modeling of $4 \mathrm{H}-\mathrm{SiC}$ VJFET inverter," IEEE Industry Applications Society Annual Meeting, October 2-6, 2005, Hong Kong, China, pp. 2630-2634.

[8] F. Blaabjerg, J. K. Pedersen, "Optimized design of a complete three phase PWM-VS Inverter," IEEE Transactions on Power Electronics, vol. 12, no. 3, May 1997, pp. 567-577.

[9] C. Wong, "EMTP modling of IGBT dynamic performance for power dissipation estimation," IEEE Transactions on Industry Applications, vol. 33, no. 1, Jan./Feb. 1997, pp64-71.

[10] V. Blasko, R. Lukaszewski, R. Sladky, "On line thermal model and thermal management strategy of a three phase voltage source inverter," IEEE Industry Applications Society Annual Meeting, October 3-7, 1999, Phoenix, Arizona, pp.1423-1431.

[11] B. Ozpineci, System Impact of Silicon Carbide Power Electronics on Hybrid Electric Vehicle Applications, Ph.D dissertation, The University of Tennessee, Aug. 2002.

\section{APPENDIX II. MODELING OF INVERTER}

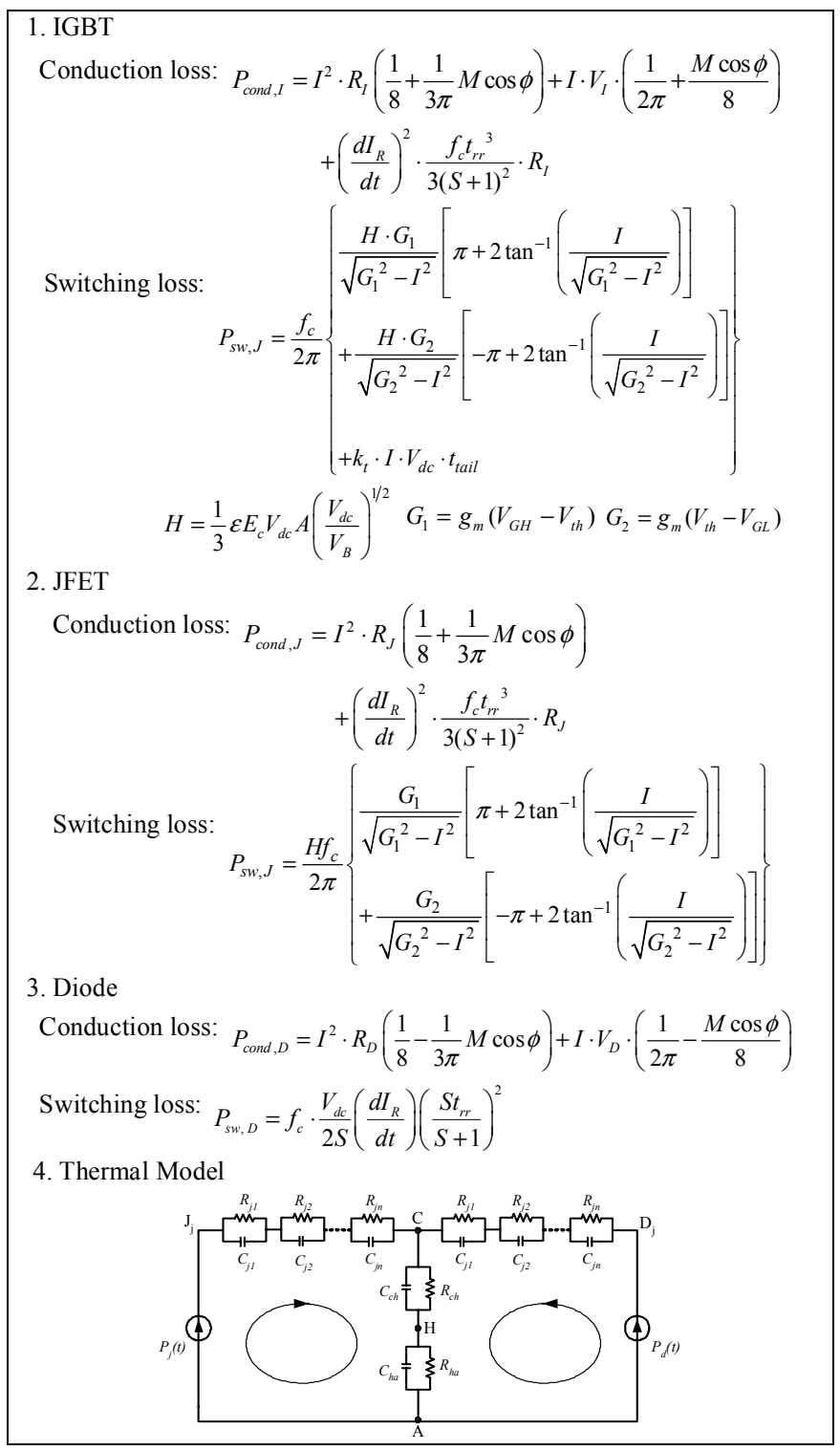

